\title{
ITS ON RAILWAY
}

\author{
MARTIN LESO \\ Czech Technical University in Prague, Faculty of Transportation Sciences, Praha, Czech Republic \\ correspondence: leso@fd.cvut.cz
}

\begin{abstract}
Development of technology management and security, transmission and information systems allows the concept of process management and security of railways and organizing the operation of a new, as yet non-phase in a non-traditional way. Requirements for higher efficiency, accuracy and flexibility of the attractiveness of rail transport Connection in the integrated transport systems are a challenge for the railways. These requirements can be solved just by changing the concept and technology of the presented here as an ITS-R.
\end{abstract}

KEYwORDS: ERTMS/ETCS, GSM-R, Inteligent traffic systems on Railway (ITS-R), Traffic management systems (TMS), Railway control and command systems (CCS).

\section{STATE OF THE ART}

Modern technologies are applied for control, command and signaling and in the area of information systems (for both control and passengers check-in) on the Czech Railway. Electronic systems are installed (station electronic interlocking systems, crossing interlocking system and etc.) including remote control systems (central dispatching center). Information systems allow to enter process and provide data to be able to control direct and on strategic level control and plan of railway transport. Systems also provide information to passengers via panels and monitors. Today's approach is focused towards to install interlocking technologies on the infrastructure and the problems related to the movement of vehicles are missed out. Vehicles are equipped by systems checking the driver's watchfullness and by the LVZ system transmiting signals to the driver's cabine. But, the responsibility of reading signals and satisfy all rule remains on the driver himself. About $1500 \mathrm{~km}$ of the Czech corridors is equipped by the system LVZ. Remaining parts of the infrastructure have no LZV and the driver is monitored only by periodical vigilance button pushing.

This state of the art is analogical in EasternEuropean countries (Poland, Slovakia, Hungary). Some vehicles ( $\breve{C D} 471$ series) are equipped by intelligent technology ATO (Automatic Train Operation), denoted AVV in Czech language, that makes possible to automate vehicle and driver's work control. These systems lead to decrease operating costs but their wide application is not optimal now due to missing pieces of information from the infrastructure and absence of safety level of vehicle driving. Despite the AVV system developed in the Czech Republic reached excellent operating parameters on the world level.

ERTMS implementation plan was ratified and published in 2014. This plan is a crucial document to define the ERTMS implementation strategy in the Czech Republic. The fundamental change (in compar- ison with existing plans) is a new strategy to equip vehicles by "ETCS onboard part". On the continuous track sections equipped with ETCS of hundreds of $\mathrm{km}$ length immediately after entry into service will be prohibited trains without functional compatible vehicle On-board ETCS. It is planned to equip about 1000 vehicles by ETCS onboard system up to 2020 and about 1500 vehicles up to 2024 . It may be stated the most vehicles will be equipped by ETCS. But ERTMS implementation plan is concerned only to TEN-T track net, other track net is not supported yet. The Czech rail net included core TEN-T track with length of $1329 \mathrm{~km}$ (3670 km of rails), others tracks TEN-T $1265 \mathrm{~km}(3022 \mathrm{~km})$, other main tracks of the length $2430 \mathrm{~km}(3633 \mathrm{~km}$ kolejí) and $4409 \mathrm{~km}(5079$ km kolejí) of regional tracks. European legislative TSI (Technical Specifications of Interoperability) defines requests to adapt main and regional rails outside of TEN-T including all vehicles and industrial vehicles to be interoperable, i.e. ETCS compatible. The issue of dealing with these types of lines forming around 2 / 3 of railway network in Czech Republic, therefore remains a major challenge for the future. The ERTMS Implementation plan prepare the implementation of ITS-R systems well. With regard to the locomotives complete on board ETCS fulfilment, both national main line and regional lines shall be calculated to be vehicles to be equipped with ERTMS / ETCS on-board units.

The assumption of full ERTMS/ETCS onboard fulfillment is the big opportunity for change scope and type of interlocking technologies installed on infrastructure. Today's "full" installation with railway interlocking systems (station, track and level crossing systems with signals, track circuits od axel counters and etc.) on this types of tracks aren't full installed not yet. On focus mainly to the regional tracks, using of conventional interlocking systems is not economical justified. These types of track are therefore suitable for installation of ERTMS/ETCS systems, mainly 
ETCS - Level 1, or ETCS - LS mode.

Most forward-looking of all functions with regard to ITS systems may be ETCS - L3 (currently validated as ERTMS / ETCS Regional). With these systems may also consider the use of new technologies GNSS, which are not yet in place in the TSI, but there may be early implemented.

On this types of tracks, on the corridors main tracks to, it is possible to minimalize investment and services costs by choosing the strategy and type of control of the railway system based on minimalizing of parts of infrastructure technologies with reduction of signals and vehicle detection systems. It is necessary to consider, having regard to its applicability of technologies, the use of radio communication between vehicle and infrastructure. They must also be addressed, in particular freight train integrity to enable the detection systems in infrastructure. In 2015 was also approved and published other strategic document of Ministry of Transportation of Czech Republic (MD ČR), the "action plan ITS", which also deals with the implementation of ITS to rail.

Action plan for ERTMS / ETCS and its implementation in the Czech Republic and, in principle, only referred to the downstream transport technologies (remote control, automation driving, etc..). The overall system is the concept of ITS in rail. In another development, it is therefore advisable to ERTMS / ETCS, GSM - R and its one unit, in order to implement appropriate design and integration of all systems to ensure the function of ITS - R.

\section{EUROPEAN BEST PRACTICES}

Western European countries, the issue of long-term facilities of vehicles already addressed since 1950 mainly due to the provision of safe movement of vehicles. For example, German Railway has wholly Used vehicle systems controlling train movements (LZB main lines, branch lines PZB). Very high level of amenities vehicles ERTMS / ETCS (Level LS, Level 2) currently have Swiss Railways. For example, German Railways has a wholly owned Equipment vehicles systems controlling train movements (main line system LZB, PZB byline). Very high level equipment of vehicles ERTMS / ETCS (level LS, step 2) currently has Swiss Railways.

In Europe and globally range, can be seen guideline facilities especially vehicle management systems for rail traffic on the principles of ERTMS / ETCS. ERTMS / ETCS is promoted by the European Union as one of the subsystems to ensure the interoperability of the whole rail system in Europe. ERTMS / ETCS ensures compliance with the requirements of the ITS-R in particular parameters ensure the safety of vehicle movement. Other parameters, such as reliability and operational efficiency, are more dependent on the conditions of application of the system in specific countries. A comprehensive approach to ITS technology is not yet defined, but it is limited to defining the

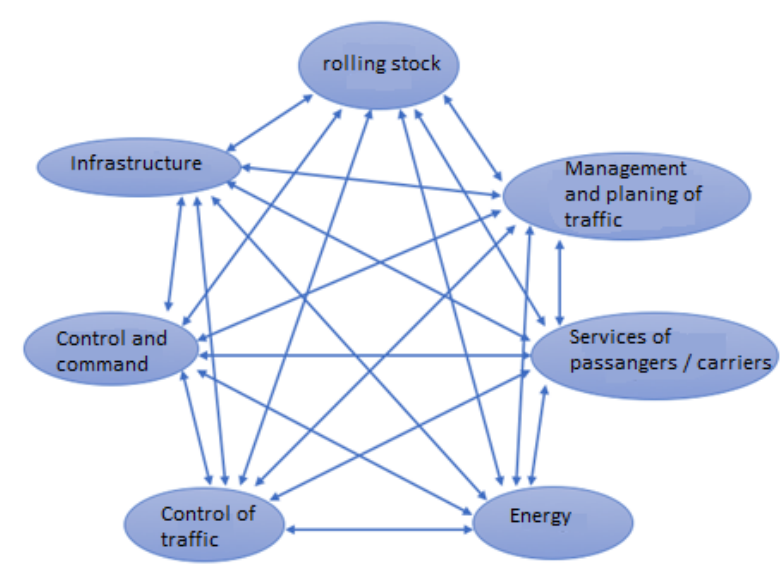

FIGURE 1. Interlinkages partial rail subsystems in ITS-R.

structure of the exchange of data on passenger and freight (TAF, TAP) - Subsystem of telematics applications for freight and passenger transport. In the area of intelligent transport systems can be seen similar trends as in the Czech Republic, ie. centralizing operations management together with the strong support of information systems for traffic management, but at the European level is already increasingly applied in real operation automatic setting routes, including optimizing traffic management (ie. The Swiss system RCS). apply new systems for the management and security of railway traffic.

\section{SySTEM APPROACH TO RAILWAYS}

The subject of deployment of the railway is an intelligent transport system whose architecture and elements are interconnected in order to optimize and increase the efficiency of the whole process (Fig. 1). ITS overall concept must be focused on increasing the parameters of the rail system, particularly the safety, reliability, economic efficiency operation.

Assumption for the goals of ITS on the rail is availability of all vehicles as a main target in the system, which provides transport (goods and people). These include the installation of ERTMS / ETCS system including automatic train control, wireless data transfer by train (GSM-R). These basic components enable implementation of the concept of intelligent vehicle concept, which ensures the function as safe motion control, as well as optimizing its movement. For proper operation of intelligent vehicles, it is necessary to equip the corresponding intelligent infrastructure that will provide adequate information, intelligent vehicles with the least economic and technical complexity. A necessary condition is also coverage of wireless twoway communication infrastructure, which can provide information not only for the management and operation, but it will also provide an information service for dispatching and public services to passengers.

Target status should lead to the integration and overall optimal solutions to the infrastructure, and 


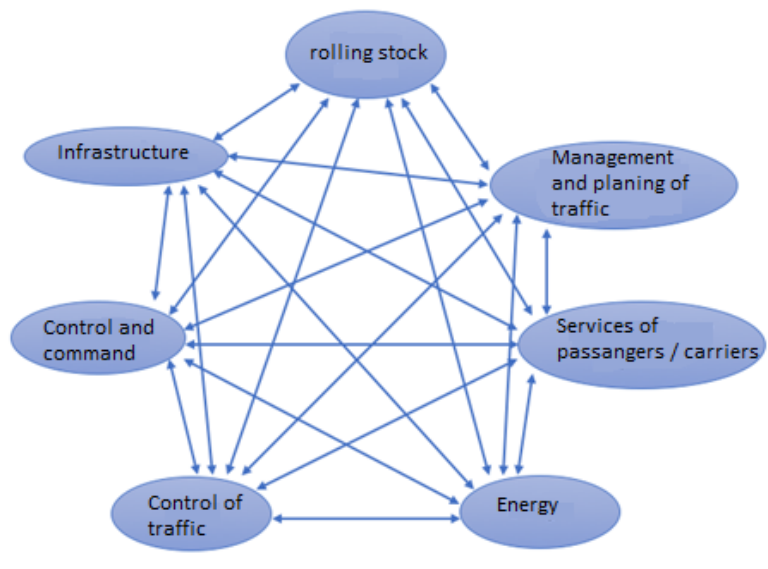

Figure 2. Conceptual vision of ITS-R.

especially on vehicles with the aim of using all the components for securing the services of ITS-R. To ensure sufficient functionality and quality of services must be technology-R ITS implemented using modern telecommunications and emerging technologies.

As a basis for solving the safety features of the system (of trains) must be the movement of all vehicles within the control signaling system ERTMS / ETCS (Fig. 2. Part draw black). These systems need infrastructure equipment GSM-R system. According to the chosen level of ERTMS / ETCS infrastructure must be equipped with the appropriate infrastructure components. For ETCS-L1 (LS) and ETCS-L2 infrastructure must be fully equipped with conventional technology infrastructure. ETCS Level-L3 enables significant savings on the side of infrastructure facilities, conventional systems management and security are not necessary and are fully replaced by technology on the vehicle condition to ensure the integrity (integrity) of the train.

To increase efficiency and optimize operations management, increase infrastructure capacity, reduce operating costs (fuel consumption and energy use, vehicle wear and infrastructure) is required all vehicles equipped with automatic train control system. This subsystem most of the information for their activities (information on the line, the vehicle allowed to travel etc ..) can be obtained through a signaling system ERTMS / ETCS.

To ensure greater attractiveness of traveling using modern information and check-in systems and logistics services for parent carriers and their customers is also needed to ensure coverage of railway infrastructure, high-speed data services (eg. The technology 4G/ 5G; Fig. 2. showing green and red). High speed data connectivity is to be ensured in all vehicles, i.e. not only driving the vehicle but also to all connection (in the case of complete sets embedded) vehicles.

\section{Advantages of the Benefits of ITS DEPLOYMENT AT RAILWAY}

The introduction of intelligent transport systems on the railways should provide ways to increase the efficiency of the entire transport system in the Czech Republic:

(1.) State managers of transport infrastructures:

(a) Increasing the capacity of transport infrastructure

(b) Increasing transport reliability, minimize delays

(c) Reducing wear of the transport infrastructure

(d) Efficient rail transport with possibility of creation the integration transport systems with using railways as the transport backbone

(e) Optimization of investment in transport infrastructure

(f) Increasing the level of safety throughout the rail network (thanks to the strategy is to increase the safety of the entire network, after which the vehicle is moving under conditions appropriate infrastructure facilities)

(2.) Railway carrier and passangers:

(a) a. Reduction of vehicle operation costs (energy, operating costs)

(b) Reducing of traffic accidents

(c) Increasing the attractiveness of rail transport for passengers

(d) Increasing the attractiveness of rail transport for freight transporters

(e) Increasing the attractiveness of rail transport for carriers (passenger and freight)

(f) Increased profits from transport

(3.) Railway industry:

(a) An opportunity for the development and implementation of new products and services

(b) Exports of modern technology with the potential to assert themselves on foreign markets

\section{Final CONCLUSION}

This paper describes the concept of new technology for the management and security of railway traffic solutions enable intelligent transportation systems. At present day, all the key technologies are developed yet. If we want to fulfill the above-mentioned strategic action is needed as soon as possible to start with a pilot project of the ITS-R. The pilot project should be implemented at the appropriate regional railway track, which will be verified and mastering functionality of the various sub-components and the whole concept of traffic management. The subject of verification should be technology ERTMS / ETCS L3 system including automatic train control, information and communication systems to ensure transmission of data necessary for the management and operation, logistic processes and services for passengers. After this necessary phase of technology adoption may be 
considered for their further expansion into the real network traffic lanes regional and national railways. The main benefit of technology ITS-R is not only to increase safety on the regional railways, but also increase the flexibility and the possibility of significant automation and optimization of traffic on main line of railways. Consequences should be in greater competitiveness and attractiveness of rail transport. 